\title{
Geologia Eclesiástica no triângulo histórico paulistano: a diversidade geológica na divulgação das Geociências
}

\author{
ECCLESIASTICAL GEOLOGY IN THE HISTORICAL TRIANGLE OF THE CITY OF SÃO PAULO: GEOLOGICAL DIVERSITY IN THE \\ DISSEMINATION OF GEOSCIENCES
}

\author{
Diego Ferreira Ramos Machado ${ }^{1}$, Eliane Aparecida Del Lama² \\ IInstituto de Geociências, Universidade de São Paulo. Mestre pelo Programa de Mineralogia e Petrologia. e-mail: diferama@hotmail.com \\ 2Instituto de Geociências, Universidade de São Paulo
}

\author{
Manuscrito: \\ Recebido: 24/06/2014 \\ Corrigido: 06/03/2015 \\ Aceito: 05/05/2015
}

Citation: Machado D.F.R. , Del Lama E.A.. Geologia Eclesiástica no triângulo histórico paulistano: a diversidade geológica na divulgação das geociências. Terræ Didatica,11(3):138-149. < http://www.ige. unicamp.br/terraedidatica/> .

Keywords: Mineralogy, Cultural heritage, Ecclesiastical geology, Geotourism, Cathedral of São Paulo.
ABSTRACT: Ecclesiastical Geology has developed around the world, helping to preserve the history and cultural heritage and promote the Geosciences. It is a part of Urban Geotourism and has gained ground in tourist activities. São Paulo, among the world's largest megacities, has not lagged behind: its rich history has much to contribute to this segment. This paper discusses the Historical Triangle of the city of São Paulo, which in its vertices has three churches (Basílica Nossa Senhora da Assunção, belonging to the Monastery of São Bento, the church of São Francisco and the church of Terceira Ordem do Carmo), besides the Metropolitan Cathedral and the church of the Pateo do Collegio - site where the city was born 461 years ago. The description of ornamental stones in churches contributes to the targeting of scientific perspectives for this segment, as this is a subject that is growing worldwide.

\section{Introdução}

A cidade de São Paulo - hoje com 460 anos - por muito tempo não se destacou muito como metrópole. Sua relevância internacional como megalópole é recente e por muitos dos primeiros anos não passava de uma vila; a Vila de São Paulo de Piratininga. Fundada por missionários jesuítas em 1554 no Pateo do Collegio, ao seu redor surgiu um polígono, denominado Triângulo Histórico. Em seus vértices, três ordens eclesiásticas cuidaram de se instalar: os beneditinos, os franciscanos e os carmelitas. Já os jesuítas, como a história registra, foram expulsos de São Paulo em 1640 e banidos do reino e domínios portugueses pela política pombalina em 1759, o que transformou o sítio de fundação da cidade em Palácio do Governo, sede da Província.

Por isso, se faz interessante estudar a cidade de São Paulo a partir do seu gérmen: as congregações religiosas. Elas fomentaram o crescimento da pequeníssima vila e deram a ela muito de suas características. Entender essa intrincada rede de relações possibilita compreender também as geo- ciências, já que é possível se extrair muito desse Triângulo Histórico a partir das rochas ornamentais. Localiza-se na bacia cenozoica de São Paulo (Augusto et al. 2003); a hidrodinâmica dos rios Tietê e Tamanduateí, seus riscos de inundações e a escolha de um local elevado, na colina do Pateo do Collegio (grafia da época), de onde era também possível avistar os campos e os invasores inimigos, colaboraram com a instalação da cidade. A determinação dos materiais de construção também é bastante típica, assim como a arquitetura paupérrima de uma vila interiorana sem muitos recursos; bem diferente das grandes cidades da época, como Salvador e Rio de Janeiro. Foi graças à riqueza advinda das fazendas de café instaladas mais ao interior, do movimento bandeirista e das indústrias que a cidade cresceu em população e economia e hoje compõe o rol das maiores cidades do globo. Com essa dinâmica foi possível melhorar as construções, importar materiais, tornar o município mais digno de sua grandeza. Hoje, no entanto, o desafio é para que se conserve/preserve esses bens 
patrimoniais que tão bem testemunham a história de uma cidade-nação como São Paulo e, para tanto, se convocam todas as ciências afins, para que se salvaguarde o testemunho histórico, inclusive as geociências e suas contribuições (ICOMOS 1965).

\section{Geologia Eclesiástica}

Os roteiros geoturísticos são uma forma bastante eficiente de divulgar os conceitos geocientíficos. Já bem consolidados na Europa e nos Estados Unidos, estão aparecendo cada vez mais no Brasil, seja do patrimônio construído, seja do patrimônio natural.

Com $84,35 \%$ da população brasileira vivendo em áreas urbanas (CENSO 2010), uma exploração do turismo que seja capaz de oferecer aos turistas e excursionistas um conhecimento e compreensão de geociências em áreas urbanas é bastante viável e poderia, além de divulgar as geociências, aumentar as receitas. Somente a cidade de Londres recebeu, em 2013, estimados 16 milhões de turistas, enquanto todo o Brasil (5.417 vezes maior do que a área de Londres) recebeu $37,5 \%$ (seis milhões) desse total. Isso significa que as cidades são altamente atrativas e contam com uma infraestrutura que colabora com a atividade turística.

As cidades tornam-se assim um grande atrativo para o geoturismo urbano. São Paulo, entre outras cidades, já conta com estes roteiros (Stern et al. 2006, Augusto e Del Lama 2011, Del Lama et al. 2015). Apesar de novidade no Brasil, em Londres existem estes roteiros há mais de três décadas (Robinson 1984, 1985). Dentro do geoturismo urbano, já começam a aparecer ramificações, ou seja, um geoturismo direcionado para partes específicas das cidades.

O termo Geologia Eclesiástica é utilizado frequentemente para descrever o estudo da pedra aplicada na construção ou ornamentação de edifícios eclesiásticos, tais como igrejas e conventos (Caetano et al. 2006). Sutherland (2000) e Potter (2005) já publicaram trabalhos que corroboraram para a adoção do termo que ainda hoje é pouco utilizado. A Geologia Eclesiástica, no entanto, tem sido mais amplamente utilizada em Portugal em trabalhos que criam circuitos geológicos com a intenção de divulgar as geociências nas cidades. Os trabalhos de Caetano et al. $(2003,2006,2007)$ ratificam que, aos poucos, o termo tende a se consolidar e colaborar com a divulgação das geociências. Stern et al. (2006) inclui a Catedral Metropolitana de São Paulo como atrativo para um roteiro geológico proposto pelo centro da Cidade de São Paulo e, com isso, começa a voltar os olhares para o tema no Brasil.

\section{Geologia Eclesiástica no Mundo}

Os assuntos eclesiásticos nos remetem sempre a Roma e não é diferente com um roteiro de geologia eclesiástica. O travertino e o tufo são as rochas mais emblemáticas da cidade eterna, mas pelo poder que representou (por ser a sede do Império), muitas outras rochas foram importadas em suas construções, incluindo as igrejas.

Os principais mármores importados, conhecidos como mármores antigos, foram extraídos durante a Roma Imperial e eram provenientes do Egito, da Ásia Menor, da Grécia, da França, da Argélia, da Tunísia e também da própria Itália (das regiões do Lazio e da Toscana). Ressalta-se que os mármores antigos (marmi antichi) não eram apenas rochas metamórficas carbonáticas, mas incluíam uma grande diversidade de tipos petrográficos tais como granito, granodiorito, tonalito, monzonito, quartzo diorito, dacito-andesito, metagabro, metagrauvaca, metaconglomerado, gnaisse tonalítico, calcário fossilífero, brecha calcária, alabastro e travertino, totalizando 41 mármores antigos (Giampaolo et al. 2008). Uma descrição dos mármores antigos podem ser encontradas em Borghini (1989), Lazzarini e Sangati (2004) e Price (2007) sendo que este último trata também de rochas ornamentais modernas e contemporâneas.

Os marmi antichi eram utilizados tanto externa como internamente em colunas, em alvenarias, em revestimentos, nos batistérios, em estátuas, vasos, cibórios e pavimentos. Um bom exemplo para se observar alguns desses mármores antigos é o Pantheon (Panteão) em Roma (Fig. 1) que desde o século VII tornou-se um templo da Igreja Católica. Nele encontramos as colunas do pronau constituídas pelo Granito Rosso di Aswan (um granito proveniente do Egito, ainda hoje em exploração e extraído desde 3.000 anos a.C.) e pelo Granito del Foro (gnaisse tonalítico proveniente do Egito). A soleira é de Africano (uma brecha tectônica proveniente da Turquia). O piso é revestido com Porfido Rosso Antico (um dacito-andesito proveniente do Egito, também conhecido como Porfido Imperial), Giallo Antico (um calcário proveniente da Tunísia), Pavonazzetto (um mármore brechado proveniente da Turquia) e Granito Rosso di Aswan. Internamente as rochas se repetem. 

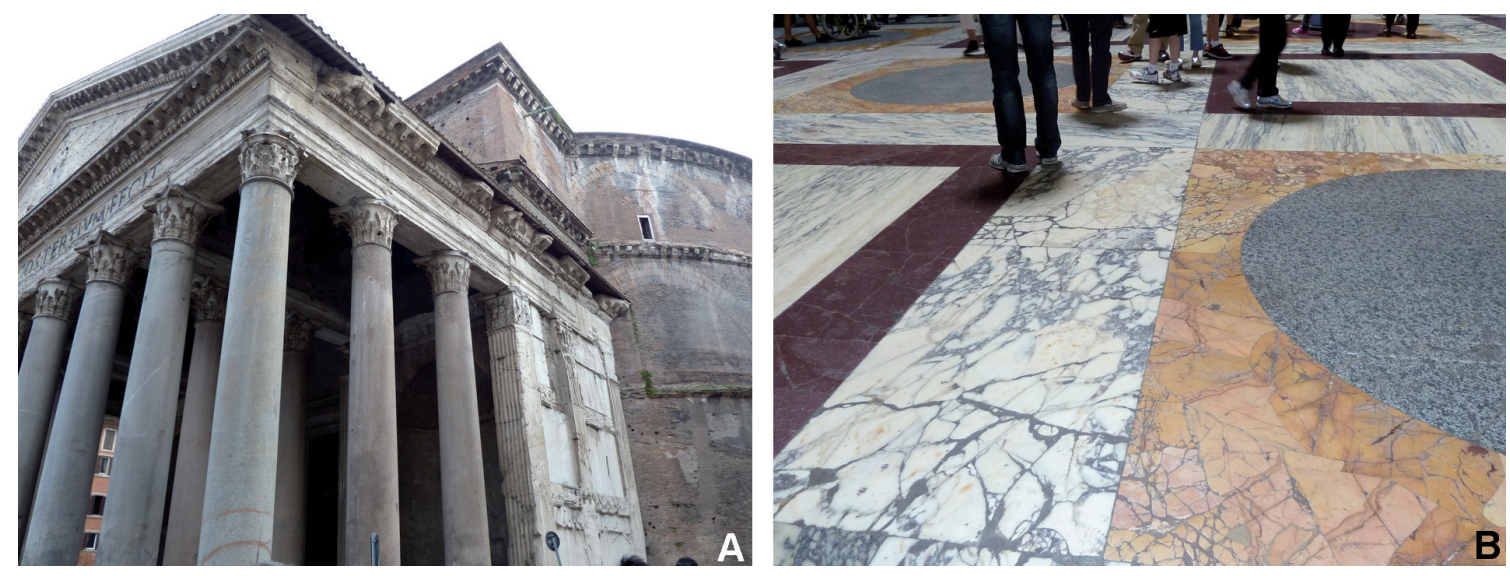

Figura 1. A. Pronau do Pantheon (Roma) com colunas de Granito Rosso di Aswan e Granito del Foro. B. Piso revestido com Porfido Rosso Antico, Giallo Antico, Pavonazzetto e Granito Rosso di Aswan.

A Basílica de São Pedro, na cidade do Vaticano (Itália), é a principal igreja do Cristianismo; sede da Igreja Católica. Ela apresenta uma diversidade de rochas, mas destacam-se os mármores Africano e Portasanta, este um calcário proveniente da Grécia e assim denominado por revestir o batente da Porta Santa presente na basílica cuja história se dá no século XV.

$\mathrm{Na}$ Abadia de Westminster, em Londres (Inglaterra), podem ser observadas as seguintes rochas: Giallo di Verona, Verde Antico, Breccia di Seravezza, Rosso Verona, Rosso Antico, Carrara, Africano, Cipolino Verde, Porfido Verde Antico (Serpentino) e Grand Antique.

No templo da Sagrada Família, em Barcelona (Espanha), ainda em construção, foram utilizadas pedras espanholas e importadas (Fig. 2). As espanholas incluem granitos (Fraquas - Lugo, Blanco
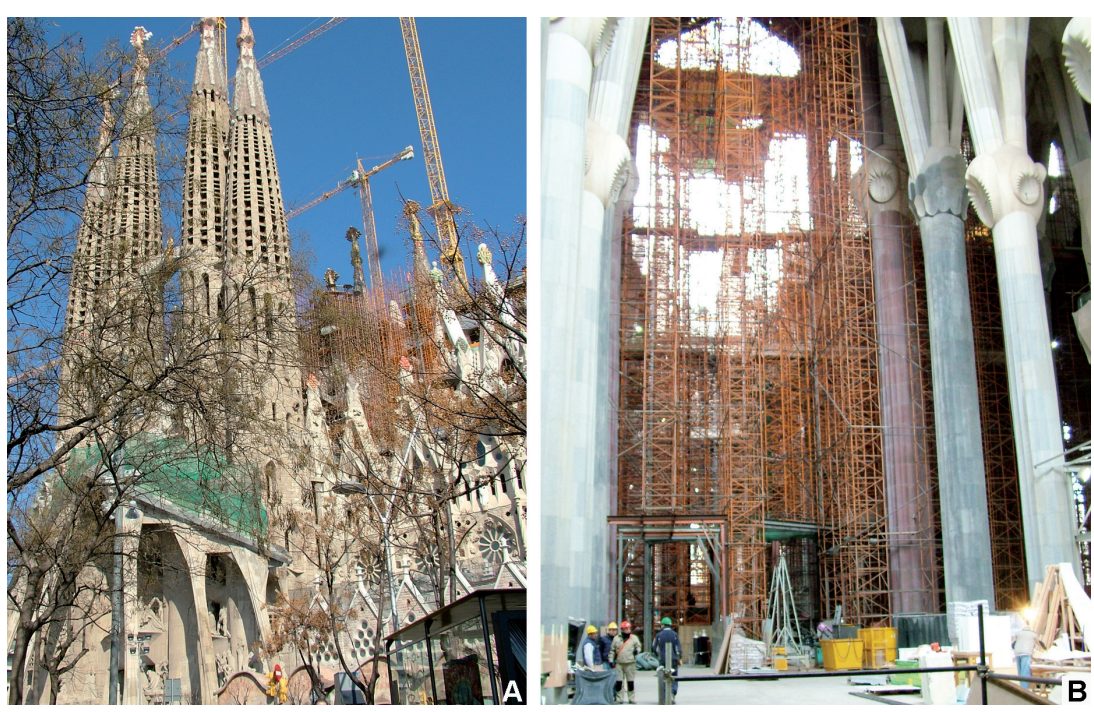

Figura 2. A. Templo da Sagrada Família em Barcelona (Espanha). B. Interior da igreja ilustrando a diversidade de rochas que está sendo utilizada em sua construção.
Cristall - Madrid, Òrrius-UII de serp - Vallès Oriental), basalto (Castellfollit de la Roca - Garrotxa), arenitos (Pedra de Montjuïc - Barcelona, Pedra de Sant Vicenç - Bages, Pedra de la Floresta - Les Garrigues), calcários (Piedra de Calafell - Baix Penedès, Pedra del Garraf - Barcelona, Pedra de la Sènia - Baix Ebre) e mármore (Blanco Macael Almeria). Da Itália provém o Basalto de Bagnoregio e o Travertino de Tívoli. Há ainda representante de pedra francesa (Granito del Tarn) e do Irã (Porfido vermelho de Yazd).

Às vezes, a rocha foi tão utilizada nas construções de uma cidade, que passa a incorporar a paisagem. É o caso da cidade de Verona (Itália), onde o Rosso Verona (Fig. 3), um calcário amonítico, é encontrado não só nas igrejas mas em todas as construções, e pode ser observado também na Basílica de São Marcos em Veneza e no Batistério de Parma. As cores rosa, verde e branco das igrejas de Florença (Fig. 4) são oriundas das rochas San Giusto di Monterantoli e Monsummano (calcário margoso), Verde di Prato (serpentinito) e Carrara (mármore), respectivamente, todas provenientes da região da Toscana. A cor creme, menos utilizada, vem do Alberese, calcário margoso proveniente da região. $\mathrm{O}$ mármore Adnet foi muito utilizado nas cidades de Viena e Salzburgo, na Áustria. 
Machado D.F.R. , Lama E.A.
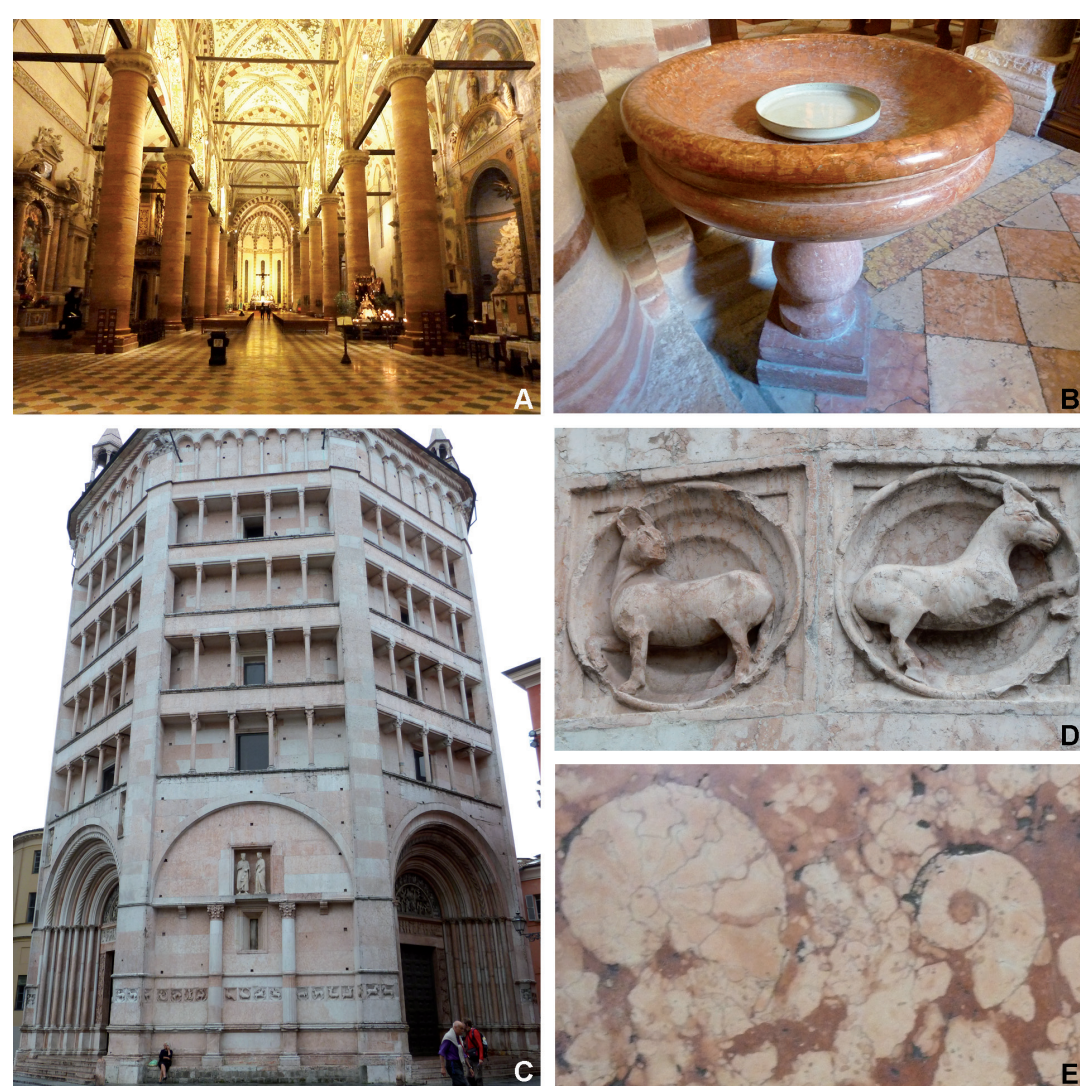

Figura 3. A. Catedral de Santa Anastácia em Verona (Itália). O Rosso Verona foi usado nos pilares e no piso, mesclando-se com mármores preto e branco. B. Pia de água benta constituída por Rosso Verona na Igreja de São Lorenzo (Verona, Itália). C. Batistério de Parma (Itália) construído com o Rosso Verona. D. Detalhe da Figura 3C. E. Amonite decimétrica no piso da Catedral de Parma.

Em muitas das igrejas em Roma encontram-se os pisos cosmatescos (Fig. 5), que consistem em mosaicos de pedra de padrões geométricos e angulares executados pela Família Cosmati durante os séculos XII e XIII. Os mosaicos eram construídos com os mármores antigos reciclados dos pisos das primeiras igrejas ou das ruínas de Roma, resultando em formas coloridas e exclusivas, ou seja: os desenhos não se repetem de uma igreja para outra. As cores mais utilizadas foram o vermelho (Porfido Rosso Antico), o verde (Serpentino, meta-andesito proveniente da Grécia), o amarelo (Giallo Antico) e o branco (Carrara, mármore proveniente da Itália). Este mesmo trabalho foi executado na Abadia de Westminster, em Londres.

No Brasil, demonstrando que o país possui grande potencial para desenvolver a geologia eclesiástica, podemos citar a Igreja de São Gabriel, em Ametista do Sul (RS), toda revestida internamente com drusas de ametista, citrino e calcita; as igrejas de estilo barroco de Ouro Preto (MG), como a de São Francisco de Assis, por exemplo, onde foram muito utilizados quartzito e esteatito (pedra-sabão); as igrejas de Salvador (BA) onde há uma presença muito marcante do Lioz (um calcário proveniente de Portugal); a Basílica de Nossa Senhora de Nazaré, em Belém (PA), onde há uma grande variedade de rochas: Rosso Verona, Lioz, mármore, serpentinito, granito, etc.; (Fig. 6) e inúmeras outras igrejas.
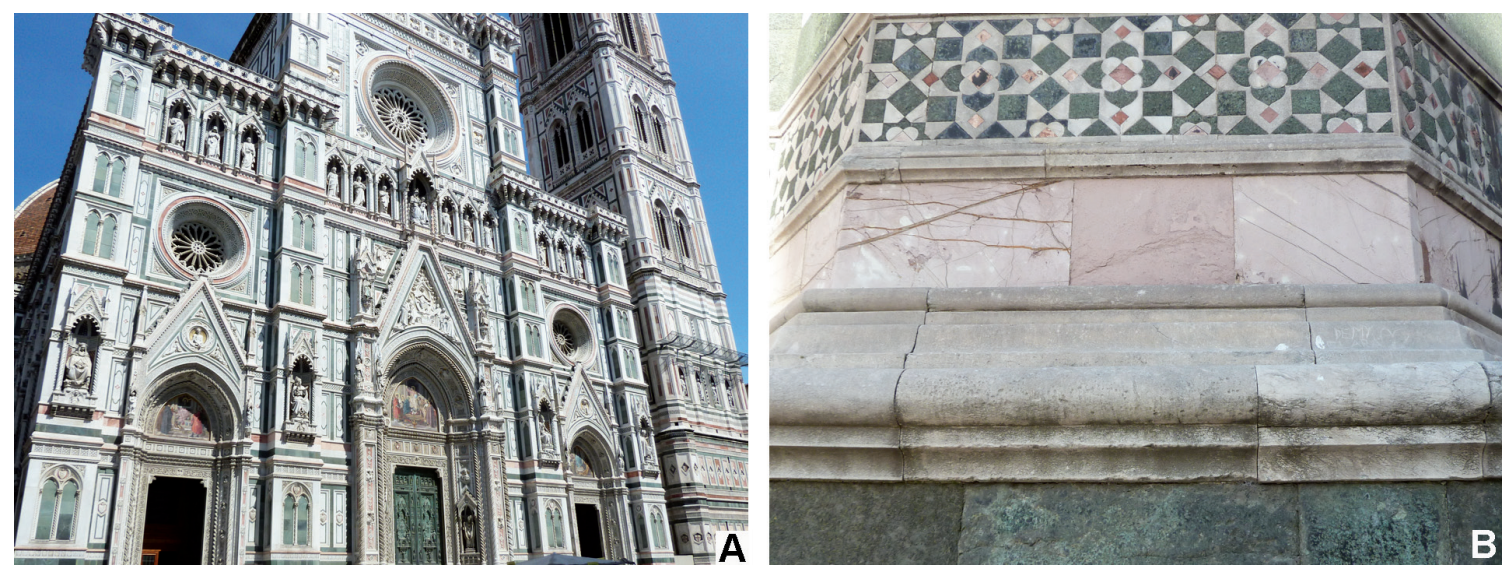

Figura 4. A. Catedral de Florença (Itália). B. Detalhe do revestimento da Catedral de Florença, destacando as três rochas principais do revestimento: calcário rosa, serpentinito e mármore branco. 

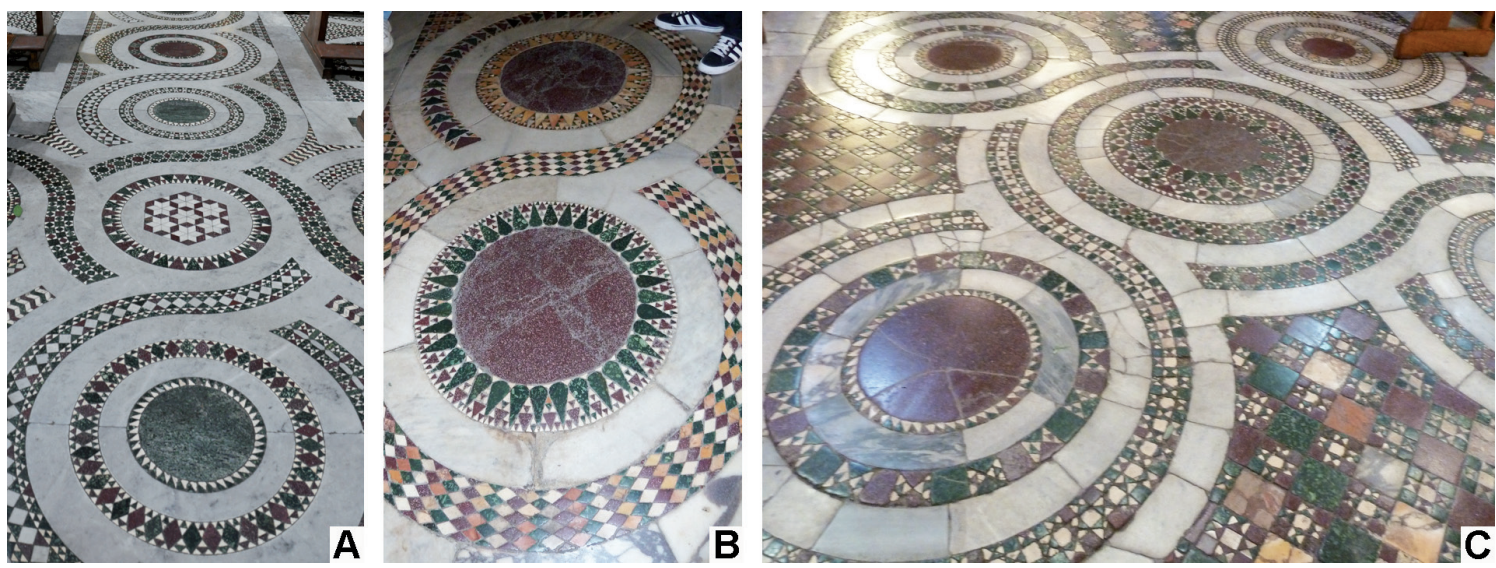

Figura 5. Exemplos de pisos cosmatescos. A. Basilica di Santa Maria in Trastevere, Roma (Itália). B. Basilica di Santa Maria in Cosmedin, Roma. C. Igreja de Santa Maria Maggiore, Tívoli (Itália).
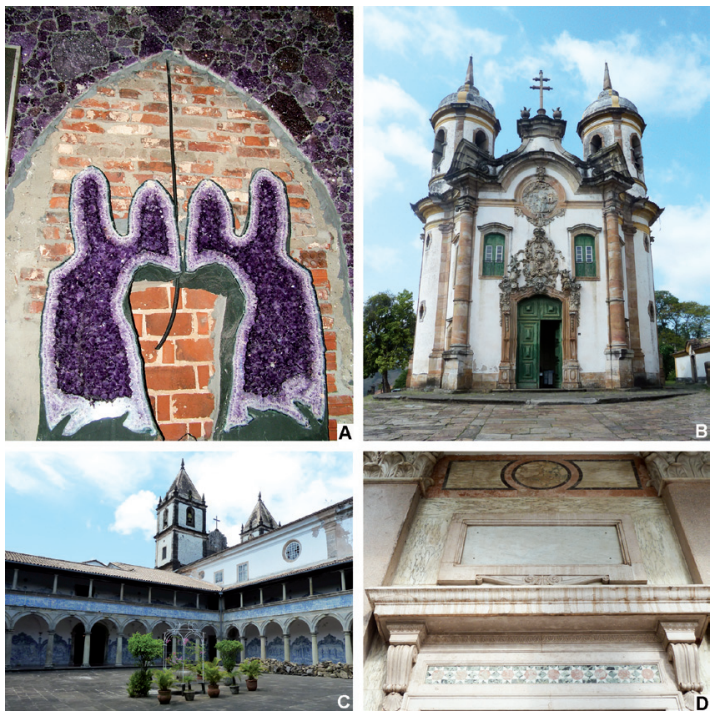

Figura 6. A. Interior da Igreja de São Gabriel, Ametista do Sul (RS). B. Igreja de São Francisco de Assis, Ouro Preto (MG). C. Claustro da Igreja São Francisco de Assis, Salvador (BA). D. Detalhe no revestimento da Basílica de Nossa Senhora de Nazaré, Belém (PA).

\section{Geologia Eclesiástica no Triângulo Histórico de São Paulo}

No Triângulo Histórico de São Paulo há edifícios eclesiásticos com maior ou menor grau de ornamentação e, portanto, com maior ou menor variedade de pedras aplicadas (Fig. 7). Estão nesse polígono: a Basílica Nossa Senhora da Assunção, pertencente ao Mosteiro de São Bento (beneditinos ou Ordem de São Bento, OSB), a igreja de São Francisco, pertencente aos franciscanos (ou Ordem dos Frades Menores, OFM), a igreja da Ordem Terceira do Carmo, pertencente a Venerável Ordem Terceira do Carmo (ou Ordem dos Terceiros Carmelitas) e a igreja de São José de Anchieta, hoje pertence novamente aos Jesuítas (ou Sociedade de Jesus, SJ), no Pateo do Collegio. Finalmente, muito próximo ao Triângulo Histórico, encontra-se também a Catedral Metropolitana Nossa Senhora de Assunção de São Paulo, cuja relevância merece citação ainda que fora do Triângulo Histórico.

O mosteiro de São Bento foi fundado em 1598 por frei Mauro Teixeira, filho de um entalhador de pedras de São Vicente e discípulo do padre Anchieta. A Basílica atual (Fig. 8), dedicada a Nossa Senhora da Assunção, é o quarto templo do mos-

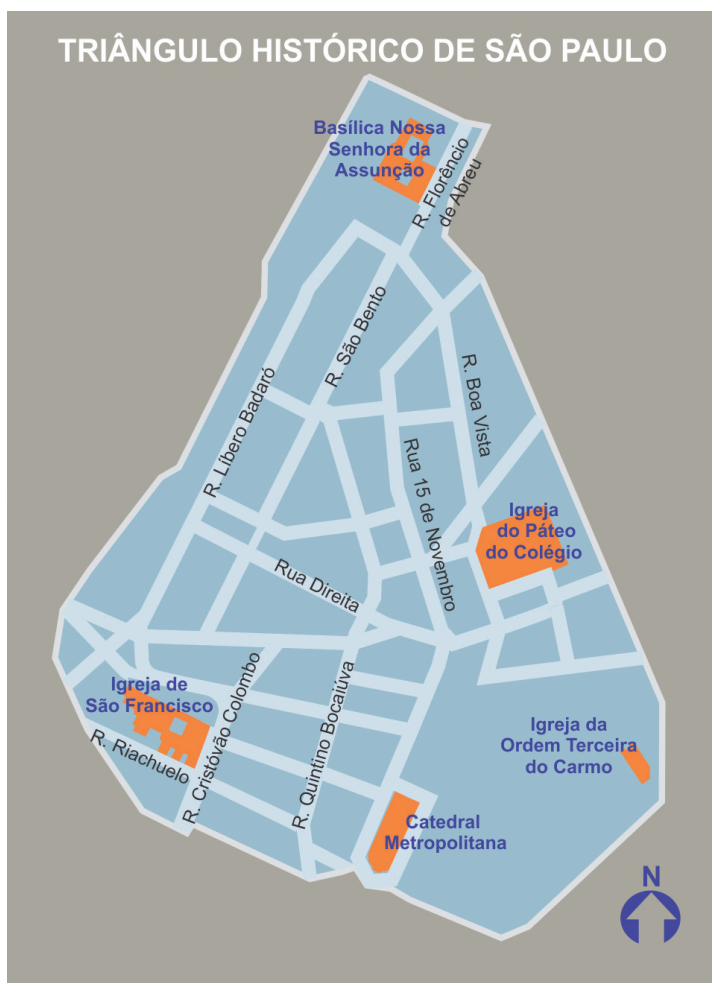

Figura 7. Localização das igrejas estudadas no Triângulo Histórico paulistano. 
teiro; o primeiro data de 1598 , o segundo de 1650, o terceiro de 1722 e o atual de 1912 (Vigna 2007). Segue o estilo Beuronense (da Escola de Arte Beneditina de Beuron, no sul da Alemanha) e os pisos, em mosaicos que lembram os cosmatescos, são, na verdade, granilite. Riquíssima em adornos, a igreja apresenta na capela lateral piso em pedras, entre elas um calcário fossilífero rico em amonitas, e uma grande variedade de tipos litológicos (Fig. 9).

A igreja de São Francisco (Fig. 10), ladeada pela igreja da ordem terceira e pela Faculdade de Direito, compõe o Largo São Francisco. No local do antigo convento surgiu a faculdade e à cidade vieram estudar grandes nomes da História do Brasil. O templo é de estilo barroco e sofreu significativas mudanças ao longo do tempo, mas data do século XVII. No chão há mosaicos com mármores e Lioz português (calcário fossilífero) de coloração rosa e Lioz branco nas paredes. Às portas encontra-se Granito Itaquera bastante alterado.

A igreja da Ordem Terceira do Carmo data de 1632 e é a única remanescente do conjunto arquitetônico do Carmo (Fig. 11).

Figura 9. Interior da Basílica Nossa Senhora da Assunção do Mosteiro São Bento. A. Clorita Mármore de proveniência desconhecida (acima) e Serpentinito Saint-Denis (abaixo). B. Pia de água benta em calcário fossilífero. C. Coluna em Granito Itaquera com marcas (manchas) de gordura, local onde as pessoas encostam a cabeça. D. Piso da capela lateral, revestido em pedras, com a presença de amonitas centimétricas. E. Detalhe da coluna do baldaquino em dacito porfirítico (Sibéria). F. Variedades de granito do Lago Maggiore.
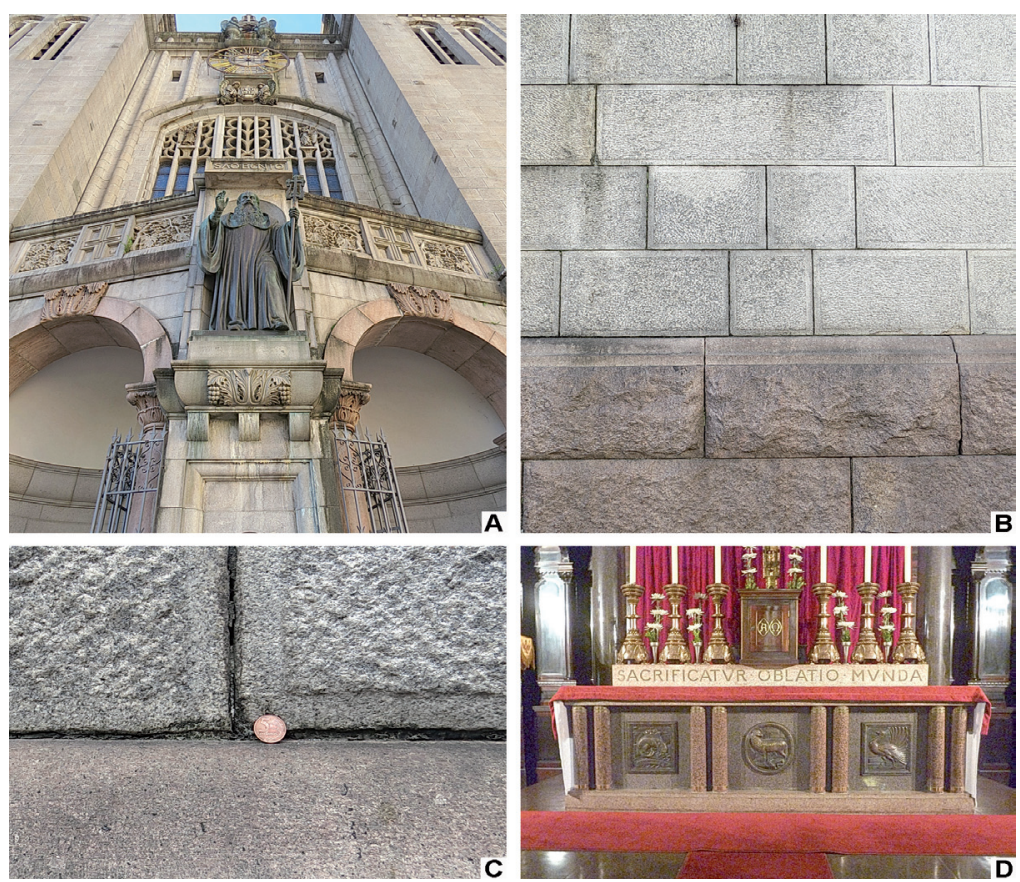

Figura 8. Basílica Nossa Senhora da Assunção do Mosteiro São Bento. A. Fachada em Granito Itaquera (SP) e Rosa Itapeva (SP); o santo em bronze. B. Base da fachada composta por Granito Itaquera (acima) e Rosa Itapeva (abaixo). C. Detalhe do corte das pedras. D. Altar-mor da Basílica, composto por granitos do Lago Maggiore (Itália): de cor de rosa, de cor cinza e de cor vermelha.
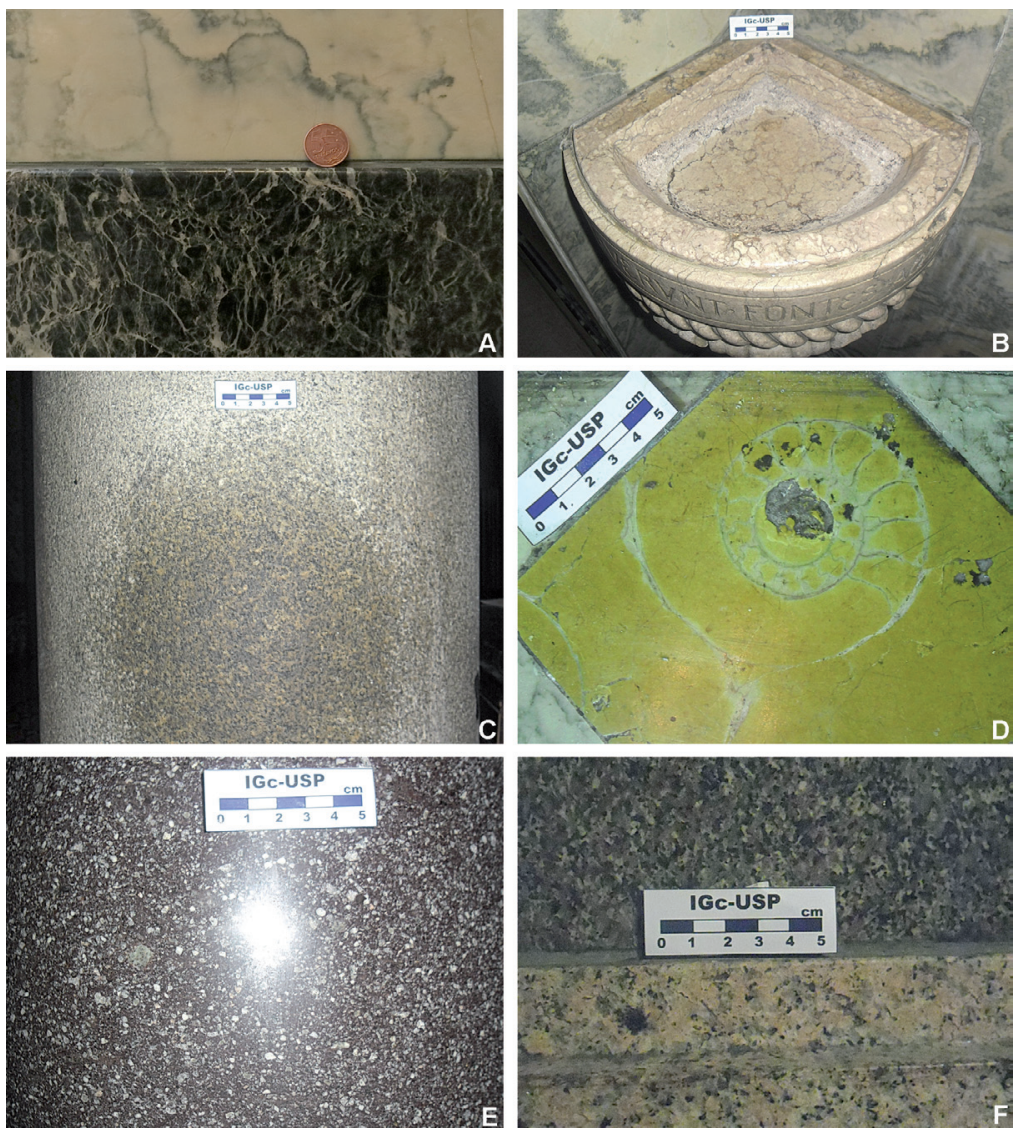

ISSN 1679-2300 

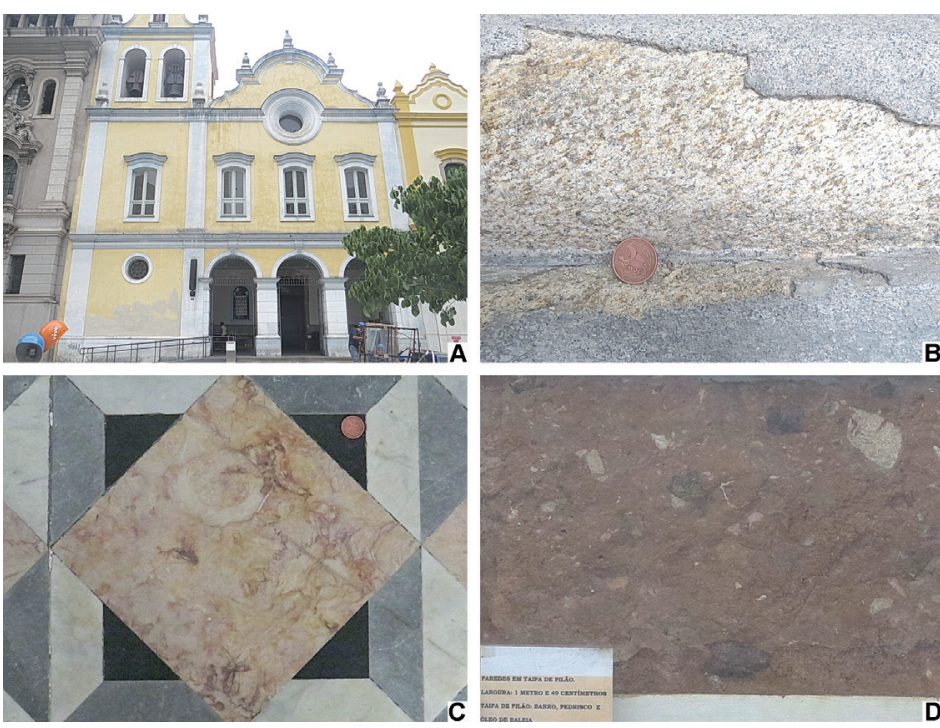

Figura 10. Igreja de São Francisco. A. Fachada. B. Detalhe da alteração do Granito Itaquera, com desplacamento de correções feitas em granilite. C. Mosaico no piso do altar composto por mármores (de cores cinza, branco e preto) e Calcário Fossilífero (Lioz português). D. Janela de demonstração da parede, feita em Taipa de Pilão.

Além daquela havia, no largo do Carmo, a igreja e convento do Carmo (de 1594), construídos no local da forca, em terras doadas por Brás Cubas - fidalgo e explorador português - e que foram demolidos em 1928 para a construção da Avenida Rangel Pestana (Verderame 2010). O estilo é barroco e há na fachada Granito Itaquera, bastante alterado, e nas pias de água benta Lioz; no chão o mosaico é composto de
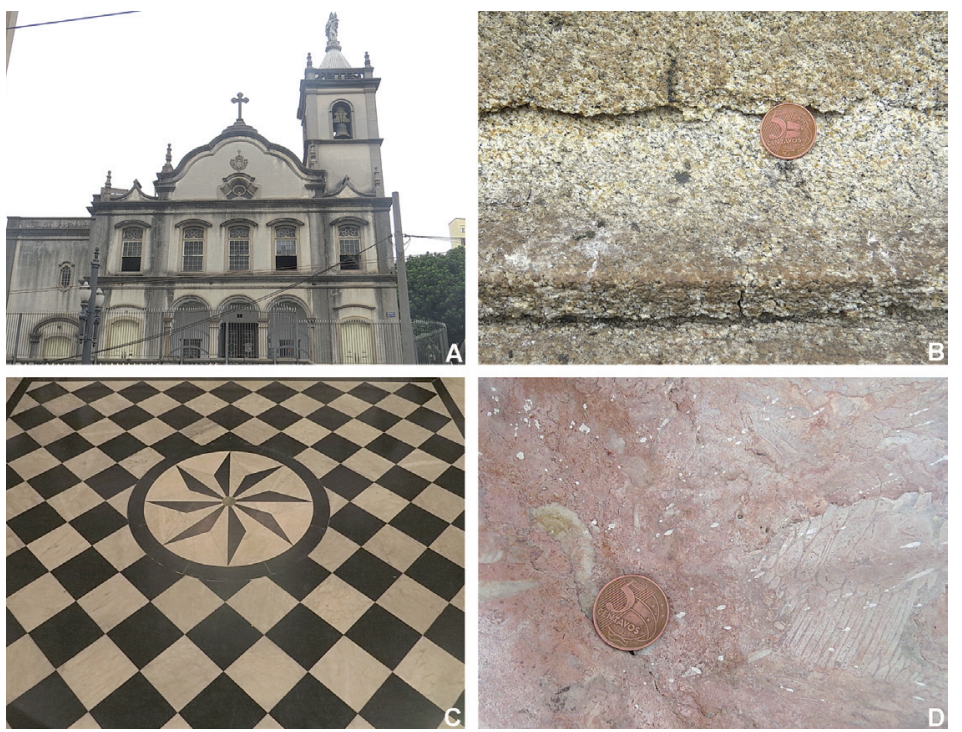

Figura 11. Igreja da Ordem Terceira do Carmo. A. Fachada. B. Avançada alteração do Granito Itaquera, presente na fachada, já com perda de material. C. Piso em mosaico, de mármores branco e preto. D. Detalhe da pia de água benta, à entrada, feita em calcário fossilífero (Lioz português). mármores preto e branco.

Dessa forma, a variedade de rochas (georrecursos) nas igrejas do Triângulo Histórico é apresentada nas Tabelas de 1 a 3 .

Também está presente no Triângulo Histórico a igreja das Chagas do Seráfico Pai Francisco (pertencente à ordem terceira ou Ordem Franciscana Secular, OFS), recentemente restaurada, e é contígua à igreja de São Francisco dos frades menores e compõe o Largo São Francisco junto à Faculdade de Direito da Universidade de São Paulo, também barroca.

O Pateo do Collegio, antes de ser a atual réplica do colégio de outrora, abrigava a sede do Palácio da Presidência da Província e seu largo era denominado Jardim do Palácio (Fig. 12). Em 1896 foi demolida também a igreja, ampliando-se o Palácio, que ganhou uma fachada de estilo neoclássico e um pórtico tetrastilo, atribuído ao engenheiro-arquiteto Eusébio Steavaux, com as colunas encimadas por dosséis jônicos. Também se atribui a Steavaux outras reformas, entre elas a da Faculdade de Direito do Largo São Francisco, já que lhe parece típico essa forma de composição única na São Paulo dos anos 1880. Campos (2009) afirma que o engenheiro francês empregava em suas obras mármores verdes/brancos/ pretos originários de sua fazenda no Pantojo, na região de Alumínio (SP). Pela presença de três capitéis jônicos remanescentes no Museu Anchieta (junto ao Pateo do Collegio) e que pertenceram ao antigo Palácio, afirma-se que não se tratavam de mármores verdes, mas de filito semelhante ao do Grupo São Roque, e que a quarta peça do tetrastilo compõe hoje a base do altar da Catedral Metropolitana de São Paulo, após permanecer por anos na Mitra Arquidiocesana de São Paulo, no bairro de Higienópolis, até que Dom Odilo P., cardeal Scherer, arcebispo metropolitano de São Paulo, solicitasse que daquela peça fosse confeccionado o novo altar da Catedral. Outra peça, do mesmo filito e 
Machado D.F.R. , Lama E.A.

Tabela 1. Rochas ornamentais presentes na igreja de São Francisco

\begin{tabular}{l|l|l}
\hline Litologia & Designação comercial & Proveniência \\
\hline Calcário fossilífero & Lioz & Portugal \\
\hline Granito & Cinza Mauá & Ribeirão Pires (SP) \\
\hline Granito & Itaquera & São Paulo (SP) \\
\hline
\end{tabular}

Tabela 2. Rochas ornamentais presentes na igreja da Ordem Terceira do Carmo.

\begin{tabular}{l|l|l}
\hline Litologia & Designação comercial & Proveniência \\
\hline Calcário fossilífero & Lioz & Portugal \\
\hline Granito & Itaquera & São Paulo (SP) \\
\hline Mármore & Mármore branco & (desconhecida) \\
\hline Mármore & Mármore preto & (desconhecida) \\
\hline
\end{tabular}

Tabela 3. Rochas ornamentais presentes na igreja do Mosteiro de São Bento (Basílica Nossa Senhora da Assunção).

\begin{tabular}{l|l|l}
\hline Litologia & Designação comercial & Proveniência \\
\hline Calcário fossilífero & Rosso Verona & Itália (Verona) \\
\hline Dacito & Pórfiro vermelho & Sibéria \\
\hline Granito & Itaquera & São Paulo (SP) \\
\hline Granito & Rosa Itupeva & Itupeva (SP) \\
\hline Granito (de cor cinza) & & Itália (Lago Maggiore) \\
\hline Granito (de cor rosa) & & Itália (Lago Maggiore) \\
\hline Granito (de cor vermelha) & & Itália (Lago Maggiore) \\
\hline Mármore & Carrara & Itália (Carrara) \\
\hline Mármore (de cor amarela) & & (desconhecida) \\
\hline Serpentinito & Vert des Alpes & Itália \\
\hline
\end{tabular}

que permanece sem procedência e histórico, é uma mesa que se localiza no Jardim da Luz. A igreja do Pateo do Collegio conta com Granito Cinza Mauá nas colunas do arco e na soleira da porta principal (Fig. 13). Ela data da década de 1970. A última reforma recebeu influência do arquiteto Claudio Pastro, quando recebeu Granito Itu na pia batismal e, provavelmente, Granito Capão Bonito no ambão, e mármore branco no chão das laterais.

\section{Catedral Metropolitana de São Paulo: a principal igreja paulistana}

Muito próxima ao polígono está a Catedral, denominada erroneamente de Catedral da Sé. Catedral é o nome atribuído às igrejas que abrigam a cathedra (cadeira), na qual se senta o epíscopo (o bispo, aquele que está em vigia); Sé (sedis), por sua vez, significa ver. Com estas explicações, chamar o templo de Catedral da Sé se torna redundante, sendo o mais correto denominá-la:
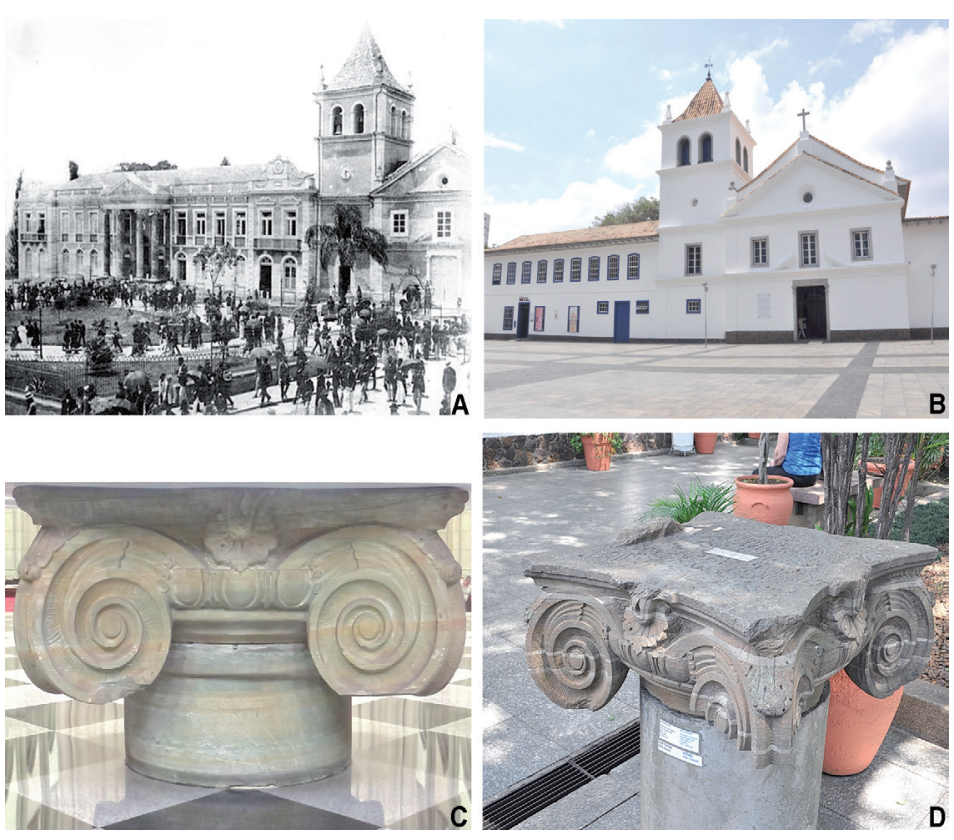

Figura 12. Jardim do Palácio e capitéis neoclássicos. A. Foto do Palácio do Governo da Província (fonte: arquivo público do Estado de São Paulo), com pórtico em tetrastilo com quatro colunas encimadas por dosséis jônicos. B. Réplica do antigo colégio e igreja jesuíta, atual Pateo do Collegio. C. Base do altar versus populi da Catedral. D. Um dos três dosséis remanescentes do Palácio, ainda presentes no Pateo do Collegio como objeto museológico. 

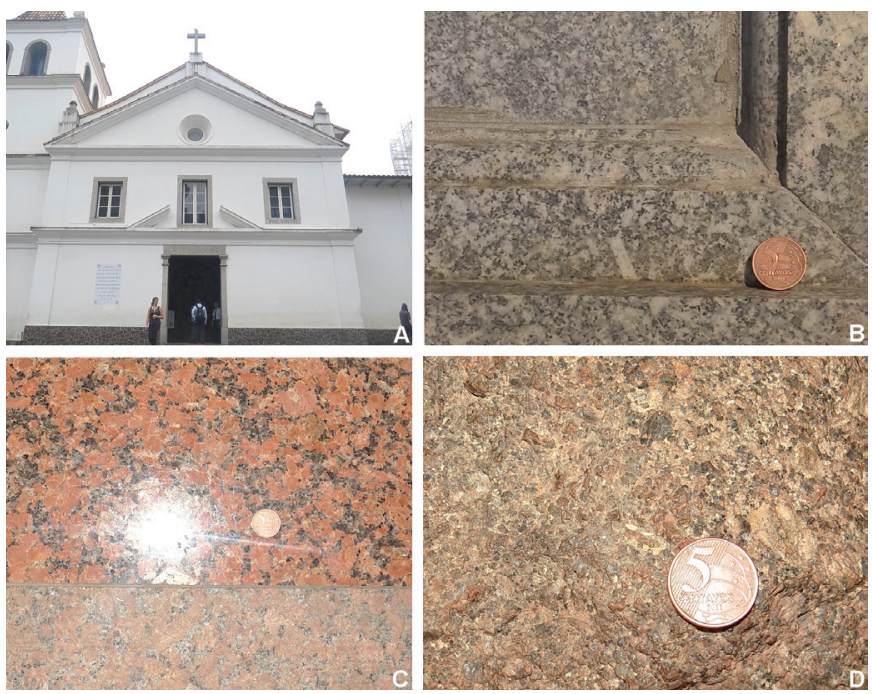

Figura 13. Igreja de São José de Anchieta, presente no Pateo do Collegio. A. Fachada. B. Detalhe do arco do presbitério, em Granito Cinza Mauá. C. Granito Vermelho, provavelmente Capão Bonito, utilizado no ambão. D. Detalhe do Granito Itu, não polido, utilizado na pia batismal.

Catedral Metropolitana de São Paulo, o principal templo da província eclesiástica e igreja-mãe da Arquidiocese de São Paulo, ou simplesmente Sé.

Por tamanha dignidade, não se concebia junto com as riquezas advindas do café, no início do século $X X$ - que transformaram a cidade num importante centro econômico - uma pequena matriz barroca desgastada pelo tempo. Foi preciso levantar um templo tão suntuoso cuja vista traduzia a imponência da metrópole. Para tanto ergueu-se em estilo neogótico um templo de mais de cinco mil metros quadrados, medindo $111 \mathrm{~m}$ de comprimento, $46 \mathrm{~m}$ de largura e atingindo uma altura de $92 \mathrm{~m}$ em suas torres (Fig. 14).

Totalmente revestida em granito nacional, o projeto inicial previa que até estes fossem importados. Um naufrágio no Atlântico e os elevados custos, aliados ao pensamento nacionalista, fizeram com que se optasse por uma pedreira na região de Ribeirão Pires donde adviria cada uma das pedras trabalhadas pelos quatorze mestres canteiros revestindo assim toda a catedral, erguida, no entanto, em alvenaria. Para as instalações mais nobres cuidar-se-ia de pedir aos mestres italianos que fizessem-nas em seus mármores conhecidos por todo o mundo; os marmi antichi.

Os Granitos Cinza Mauá e Itaquera são encontrados em todo o revestimento da Catedral, da base ao topo, com predominância do Cinza Mauá (da pedreira de Ribeirão Pires, SP); entre as esculturas, no entanto, predominam o Itaquera. Nos altares laterais (Fig. 15) estão presentes os már- mores italianos Vermelho Portasanta (de Caldana), Carrara e o Serpentinito Verde Saint-Denis (do Vale D'Aosta). No altar-mor versus Deum (voltado para Deus), na mesa da Eucaristia e também no altar da capela do Santíssimo Sacramento predomina o mármore amarelo Siena (do Monte D'Elsa), com detalhes em malaquita, do Congo (colunetas e crucifixo), e também lazurita, do Chile. O cibório é constituído em mármore branco. Na capela do Santíssimo Sacramento ainda encontram-se ônix proveniente do Vale D'Aosta nas colunas e Travertino di Tivoli no chão. No piso de toda a Catedral encontram-se dois tipos de granito (cinza e preto). Na pia batismal encontra-se mármore de Carrara e pórfiro do Egito, além de mármore amarelo Siena. No altar versus populi (voltado para o povo, pós Concílio Vaticano II), encontra-se a base de Filito São Roque (dossel pertencente ao Palácio do Governo) e mármore branco, além do Granito Preto São Gabriel. Na Cripta encontra-se monzonito (comercialmente denominado Granito Preto Piracaia), encerrando as capelas mortuárias dos bispos, conforme descreve Mattos (1992) chamando-o granito preto; alguns apresentam estufamento por infiltração ascendente e aplicação de selante; no altar da cripta nota-se Serpentinito.
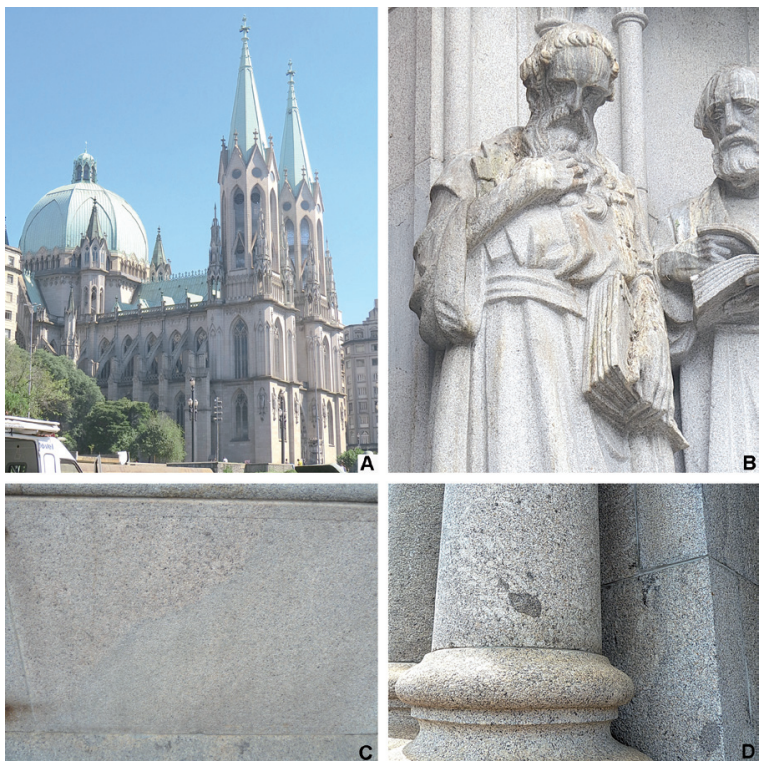

Figura 14. Catedral Metropolitana de São Paulo (Sé). A. Vista geral da Catedral com altura de $92 \mathrm{~m}$. B. Escultura em Granito Itaquera na porta da Catedral. C. Revestimento externo mostrando diferença de granulação. Largura da fotografia: $80 \mathrm{~cm}$. D. Coluna em Granito Cinza Mauá, apresentando textura porfirítica, parte superior externa da Catedral. 

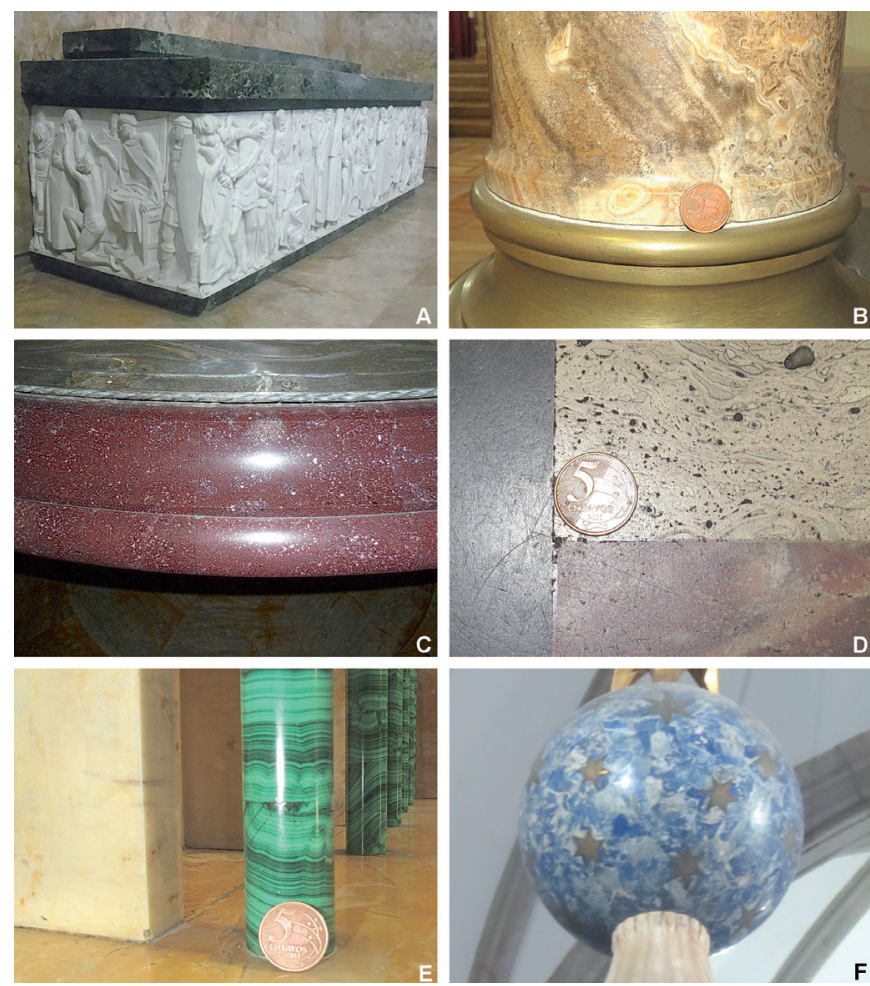

Figura 15. Interior da Catedral. A. Altar lateral em mármore branco (Carrara - Itália), Serpentinito Verde Saint-Denis (Vale D'Aosta - Itália) e Vermelho Portassanta (Caldana - Itália). B. Coluna em ônix, na Capela do Santíssimo. C. Base da pia batismal em dacito (Egito). D. Mosaico do piso da Capela do Santíssimo, com Travertino de Tívoli (Itália) e mármores vermelho e preto. E. Colunetas de malaquita (Congo), contrastando com o mármore Amarelo di Siena (Itália), fazendo referência às cores nacionais (verde e amarelo). F. Esfera em lazurita (Chile), encimando a pia batismal.

O Granito Cinza Mauá apresenta textura irregular por toda a Catedral, ora apresentando minerais porfiríticos, ora granulação mais homogênea. $\mathrm{O}$ aspecto dessa rocha na catedral não é o mais encontrado para o Granito Cinza Mauá, o que colocaria em dúvida sua utilização; entretanto, Frade (2007) afirma que foi comprada uma pedreira na região de Ribeirão Pires apenas com a finalidade de compor a Catedral. Mattos (1992) afirma que havia vantagens financeiras em importar também o granito da Europa, cuja primeira remessa foi aplicada na escadaria central da Catedral, mas a instabilidade cambial da época e o naufrágio do vapor Bogor nas costas portuguesas suspenderam a importação, forçando assim a aquisição de uma pedreira no Brasil. Na parte superior externa há blocos com feições mais usuais do Cinza Mauá.

A Tabela 4 aponta as rochas presentes na Catedral Metropolitana de São Paulo.

\section{Considerações Finais}

As cidades apresentam ricas histórias a serem contadas para as novas e futuras gerações. O patrimônio cultural, por sua vez, muitas vezes é constituído por riquezas naturais por vezes esquecidas ou até mesmo desconhecidas; é preciso resgatar esse patrimônio. Preservá-lo não somente in situ, mas também ex situ, no monumento arquitetônico. No caso da Catedral, por exemplo, o granito utilizado traz consigo toda uma simbologia. Não lhe caberia ali a alvenaria aparente, a argamassa, nem mesmo azulejos; era preciso granito duro, que simboliza a alma dos aldaciosos bandeirantes, intrépidos $e$ fortes, que atravessaram florestas e rios e dilataram o Brasil, até os contrafortes dos Andes (Leite 1954).

Além de monumentos, as igrejas paulistanas - sobretudo as do Triângulo Histórico - contam a história dessa grande São Paulo. Falam-nos de arquitetura, de geologia, de geografia e história. Merecem ser observadas cuidadosamente, estuda-

Tabela 4. Rochas ornamentais presentes na Catedral Metropolitana de São Paulo

\begin{tabular}{l|l|l}
\hline Litologia: & Designação comercial & Proveniência \\
\hline Filito & & Alumínio (SP) \\
\hline Granito & Itaquera & São Paulo (SP) \\
\hline Granito & Cinza Mauá & Ribeirão Pires (SP) \\
\hline Granito & Preto São Gabriel & São Gabriel da Palha (ES) \\
\hline Mármore & Carrara & Itália (Carrara) \\
\hline Mármore & Amarelo Siena & Itália (Monte D'Elsa) \\
\hline Mármore & Vermelho Portassanta & Itália (Caldana) \\
\hline Mármore (de cor preta) & & (desconhecida) \\
\hline Monzonito & Preto Piracaia & Piracaia (SP) \\
\hline Pórfiro & Pórfiro Imperial & Egito \\
\hline Serpentinito & Verde Saint-Denis & Itália (Vale d'Aosta) \\
\hline \hline
\end{tabular}


das para que sejam conservadas; para que se evite para com elas toda sorte de injúrias. O desvendar de situações perdidas no tempo: qual não é, se não este, o papel das geociências? A escolha de um calcário fossilífero trazido da Europa para ornamentar igrejas em São Paulo conta-nos muito do nosso desenvolvimento artístico, do nosso valor de belezas, das nossas raízes culturais. A base indígena também pode ser observada nos edifícios eclesiásticos, assim como a rica fauna e a flora brasileira talhadas em rochas duras na Catedral.

Para o turismo tudo que é novo é vital. Reler as igrejas sob uma nova ótica, a das geociências, é reinventar-se; é não deixar-se cair em esquecimento e mesmice. E às geociências cabe associar-se ao turismo para difundir-se, e auxiliando assim a sanar a lacuna cultural que existe no Brasil sobre conhecer rochas e minerais.

\section{Agradecimentos.}

Agradecemos ao CNPq pela bolsa de mestrado (processo 133279/2013-8) que possibilitou estes estudos e a Mitra Arquidiocesana de São Paulo pelo apoio à pesquisa.

\section{Referências}

Augusto J.P.S, Lopes R.C., Vasconcelos A.M., Bahia R.B.C. 2003. Bacias Sedimentares Paleozóicas e Meso-Cenozóicas Interiores. In: Bizzi 1. A., Schobbenhaus C., Vidotti, R.M. e Gonçalves J. H. eds. 2003. Geologia, Tectônica e Recursos Minerais do Brasil. Brasília: CPRM. p.55-85. URL: < http://www.cprm.gov.br/publique/media/capII. pdf> . Acesso: 27.04.2014.

Augusto W.C.B., Del Lama E.A. 2011. Roteiro geoturístico no centro da cidade de São Paulo. Terrae Didatica,7(1): 29-40. URL: <http://www.ige. unicamp.br/terraedidatica/v7 1/pdf-v7 1/TD 71_3_Wilian_Batista.pdf>. Acesso: 10.03.2013.

Borghini G. 1989. Marmi Antichi. Roma: De Luca Edizione d'Arte. 342p.

Caetano P.S., Verdial P.H. (orgs). 2007. Geologia Eclesiástica, dos Prazeres aos Anjos: um percurso geoturístico na cidade de Lisboa. Centro de Investigação em Geociências Aplicadas. Lisboa: Universidade Nova de Lisboa. 48p.

Caetano P.S., Verdial P.H., Gregório P., Heitor, A.P., Pedro B., Silva I. 2003. A criação de circuitos geológicos no Almada Forum: um exemplo de divulgação da Geologia em meio urbano. Ciências da Terra. Lisboa: Univ. Nova de Lisboa, $\mathrm{n}^{\mathrm{o}}$ esp. V, pp. 106-107; CD-ROM, pp. I24-I27.
Caetano P.S., Verdial P.H., Lamberto V., Gomes A., Freire R.. 2006. Geologia Eclesiástica na cidade de Lisboa. O exemplo da Igreja do Convento dos Cardaes. VII Congresso Nacional de Geologia. Sessão de Patrimônio Geológico. Univ. de Évora. Portugal. 4p.

Campos E. 2009. Eusébio Stevaux, arquiteto. In: Informativo Arquivo Histórico Municipal, 4(23):mar/ abr. URL: < http://www.arquiamigos.org.br/info/ info23/i-estudos-a.htm > . Acesso: 24.04.2014.

CENSO 2010. Instituto Brasileiro de Geografia e Estatística. URL: <http://censo2010.ibge.gov.br/> . Acesso: 27.04.2014.

Del Lama E.A., Bacci D.D.L.C., Martins L., Garcia M.G.M., Dehira L.K. 2015. Urban geotourism and the old centre of São Paulo City, Brazil. Geoheritage, 7:147-164.

Frade, G. 2007. Arquitetura Sagrada no Brasil: sua evolução até as vésperas do Concílio Vaticano II. São Paulo: Edições Loyola. 190p.

Giampaolo C., Lombardi G., Mariottini M. 2008. Pietre e costruito della cittá di Roma: dall'antichitá ai giorni nostri. In: Funiciello R., Praturlon A., Giordano G. eds. 2008. La Geologia di Roma - dal centro storico alla periferia. Mem. Descr. Carta Geol. D'It., 80. Florença. p. 273-406.

ICOMOS (International Council of Monuments and Sites) 1965. The Venice Charter. URL: < http:// www.international.icomos.org/charters/venice_e. pdf>. Acesso: 27.04.2014.

Lazzarini L., Sangati C. 2004. I più importanti marmi e pietre colorati usati dagli antichi. In: L. Lazzarini L. ed. 2004. Pietre e marmi antichi. Padova: Cedam. p. 73-100.

Leite Mons. M. 1954. A Catedral de São Paulo. São Paulo: Elvino Pocai. 18p.

Mattos, Mons. S. M. 1992. A nova Catedral de São Paulo. São Paulo: edição do autor. 160p.

Potter J.F. 2005. Ecclesiastical geology - a return to Victorian field standarts. Geoscientist, 15(10):4-7.

Price M.T. 2007. Decorative Stone. The complete sourcebook. Londres: Thames\&Hudson. 288p.

Robinson E. 1984. London: illustrated geological walks. Edinburgh: Scottish Academic Press. v.1. 98p.

Robinson E. 1985. London: illustrated geological walks. Edinburgh: Scottish Academic Press. v.2. 142p.

Stern A.G., Riccomini C., Fambrini G.L., Chamani M.A.C. 2006. Roteiro geológico pelos edifícios e monumentos históricos do centro da cidade de São Paulo. Revista Brasileira de Geociências, 36(4):704-711. URL: < http://rbg.sbgeo.org.br/ index.php/rbg/article/view/AE035/945> . Acesso: 24.04.2014.

Sutherland D.S. 2000. Ecclesiastical geology. In: Hancock P.I., Skinner B.J. eds. 2000. The Oxford Companion to the Earth. Oxford: Oxford University Press. p. 292-295. 
Verderame E. 2010. Histórias de Igrejas Destruídas. São Paulo: Editora Hedra. 92p.
Vigna M.B.C. (org.) 2007. Mosteiro de São Bento. São Paulo: Didática Paulista. 64p.

Resumo: A Geologia Eclesiástica tem se desenvolvido por todo o mundo ajudando a preservar o Patrimônio Histórico e Cultural e a divulgar as geociências. Compõe o Geoturismo Urbano e tem ganhado espaço junto à atividade turística. São Paulo, entre as maiores megalópoles mundiais, não tem ficado para trás: rica em história tem muito a contribuir com esse segmento. 0 presente trabalho aborda 0 Triângulo Histórico da capital paulista, que em seus vértices conta com três igrejas (A Basílica Nossa Senhora da Assunção, pertencente ao Mosteiro de São Bento, a igreja de São Francisco e a igreja da Ordem Terceira do Carmo), além da Catedral Metropolitana e da igreja do Pateo do Collegio - sítio onde nascera a cidade há 461 anos. A descrição das rochas ornamentais presentes nas igrejas contribui com o direcionamento dos olhares científicos para este segmento que tem se feito crescer em todo o mundo.

Palavras-chave: Mineralogia, Patrimônio Cultural, Geologia Eclesiástica, Geoturismo, Sé de São Paulo 